\title{
Reappraisal of Gram-staining and cultural techniques for the diagnosis of gonorrhoea in women
}

\author{
ELISABETH J. CHIPPERFIELD AND R. D. CATTERALL \\ Department of Venereology and Genito-urinary Medicine, fames Pringle House, The Middlesex Hospital, \\ London, W1N 8AA
}

\section{Summary}

A retrospective study of 209 consecutive cases of gonorrhoea showed that more than 98 per cent. of cases were detected by two sets of examinations at weekly intervals. This was compared with earlier results obtained at this clinic when only 86 per cent. of cases were detected by two examinations. It is believed that modifications in culture techniques were responsible for the improvement and that two tests are now sufficient to screen for gonococcal infection in the majority of patients when an efficient microbiological service is available.

Because of the high incidence of infection in contacts of men with gonorrhoea, a third test is recommended for the small number of such patients who have negative results of their first two tests. This also serves to monitor the efficiency of the culture techniques.

The majority of women with gonorrhoea attended because they were believed to be contacts of men with the disease but many attended of their own accord because they had symptoms. Mild symptoms were described by as many as 53.5 per cent. of all infected women.

Nine cases of gonorrhoea were detected during the follow-up period. Three of the four cases which were thought to be due to treatment failure were detected at the first test, in contrast to the cases which were thought to be due to re-infection, the majority of which were diagnosed at subsequent tests.

Constant surveillance of the accuracy of the diagnostic methods used in the detection of gonorrhoea in women is of great importance if errors are to be reduced to a minimum.

\section{Introduction}

In a report on gonorrhoea in women attending James Pringle House at the Middlesex Hospital, Catterall (1970) observed that repeated examinations were necessary to establish the diagnosis. This observation was based on the study of 300 women with vaginal discharge, 95 of whom were found to have gonorrhoea by a combination of Gram-staining and culture. Only 66 per cent. of the cases were diagnosed by the first set of investigations, 20 per cent. by the second, 10 per cent. by the third, and 4 per cent. by the fourth examination.

In view of these results it has been customary at James Pringle House to examine all new women patients and those attending with new problems at least three times and, in some cases, four times, at weekly intervals in order to exclude gonorrhoea. Since gonorrhoea represents only about 10 to 12 per cent. of the conditions diagnosed at the clinic, a large number of examinations are performed for the diagnosis of each case of gonorrhoea. An improvement in diagnostic methods would not only result in the more rapid treatment of gonorrhoea, with a consequent reduction in its spread, but would also allow a reduction in the number of examinations before the diagnosis could be excluded. This would save both time and money and would also have a beneficial effect on patients, who naturally become anxious when asked to return several times.

After the introduction of a new culture medium for the isolation of gonococci and alterations in the cultural conditions, it was decided to reassess how many examinations were necessary before gonococcal infection of the cervix or urethra could be excluded. Accordingly a retrospective study was made of all cases of gonorrhoea in women for a period of 6 months. Also included in the study were women who had attended as contacts of men with gonorrhoea but who were not found to be infected. In addition, the number of relapses or re-infections which occurred during the period of follow-up were recorded and the incidence of concurrent genital infection was noted. 


\section{Methods}

Specimens for Gram-staining and culture were taken from the endocervix and urethra with bacteriological loops. The cervix was first cleaned with a cotton-wool swab. Gramstained smears were examined by trained nursing staff. Material for culture was inoculated directly on to plates containing Columbia blood agar (Oxoid) with 0.2 per cent. yeast extract (Difco), incubated at $37^{\circ} \mathrm{C}$. in a candle extinction jar for $24 \mathrm{hrs}$, and then for a further $18 \mathrm{hrs}$ at $37^{\circ} \mathrm{C}$. in a moist air atmosphere. The plates were examined for oxidase positive Gram-negative organisms with the morphology and colonial appearance of $N$. gonorrhoeae. Sugar fermentation tests were performed to make a positive identification.

These methods differ from those used when Catterall (1970) obtained his results. At that time specimens were cultured on McLeod's chocolate agar, incubated for $24 \mathrm{hrs}$ at $37^{\circ} \mathrm{C}$. in an atmosphere of air and $\mathrm{CO}_{2}$ produced initially by the action of acid on marble chips and then, at the end of the first day, by transfer to an incubator to which a mixture of 90 per cent. air and 10 per cent. $\mathrm{CO}_{2}$ was admitted. After $24 \mathrm{hrs}$ the plates were removed and incubated for a further $18 \mathrm{hrs}$ at $37^{\circ} \mathrm{C}$. in a moist atmosphere.

The patients were normally examined at weekly intervals and the standard treatment for those with gonorrhoea was either $2 \cdot 4 \mathrm{~m}$.u. fortified procaine penicillin intramuscularly daily for 3 days or $5 \mathrm{~m}$.u. crystalline benzyl penicillin given intramuscularly in a single dose after $1 \mathrm{~g}$. probenecid by mouth. Follow-up examinations, preferably three, were performed at weekly intervals. In addition to tests for gonorrhoea, slide and culture techniques were used for the detection of Candida albicans and Trichomonas vaginalis. When infection with Herpesvirus hominis was suspected specimens were taken for tissue culture.

\section{Results}

209 women who attended James Pringle House in the first 6 months of 1973 were found to have gonorrhoea. Gonococci were detected in 91 per cent. by the first test, in $7 \cdot 1$ per cent. by the second test, and in 1.9 per cent. (four cases) at the third examination. One of the four patients who was not diagnosed until the third test was taking ampicillin at her first attendance. Another, who attended as the symptomless contact of a man with gonorrhoea, had intercourse between the second and third examination with another man who developed gonorrhoea 3 days later. The other two patients denied having sexual intercourse between the first and third examinations.

58 per cent. were detected by both Gram-stained smear and culture, 38.7 per cent. by culture alone, and 2.8 per cent. by Gram-staining alone. Five infected women $(2.4$ per cent. of the total) who were diagnosed by culture alone defaulted before treatment and could not be traced. One of them subsequently returned with salpingitis. Two of the patients who were not treated had attended because they were thought to be contacts of men with gonorrhoea.
REASON FOR ATTENDANCE (Table I)

144 women had not attended the clinic previously and 68 per cent. of them attended as contacts of men with gonorrhoea. Only 17.6 per cent. of the new patients attended of their own accord. In contrast, 47.7 per cent. of 65 patients who had attended the clinic in previous years attended of their own accord.

TABLE I Reason for attendance of 209 women with gonorrhoea

\begin{tabular}{|c|c|c|c|c|}
\hline \multirow{2}{*}{ Reason for attendance } & \multicolumn{2}{|c|}{ New patients } & \multicolumn{2}{|c|}{ Old patients } \\
\hline & No. & Per cent. & No. & Per cent. \\
\hline $\begin{array}{l}\text { Contact of man with } \\
\text { gonorrhoea }\end{array}$ & 98 & $68 \cdot 0$ & 30 & $46 \cdot 1$ \\
\hline Of own accord & 24 & $17 \cdot 6$ & 31 & $47 \cdot 7$ \\
\hline Contact of man with NSU & 11 & $7 \cdot 7$ & 3 & $4 \cdot 6$ \\
\hline $\begin{array}{l}\text { Advice of General } \\
\text { practitioner }\end{array}$ & 7 & & 1 & \\
\hline Other & 4 & & 0 & \\
\hline Total & 144 & & 65 & \\
\hline
\end{tabular}

Table II shows the percentage of women with gonorrhoea who described symptoms. Nearly 40 per cent. of those who had been requested to attend as contacts had symptoms and so did 92 per cent. of those who attended of their own accord. 53 per cent. of all the infected women were symptomatic. In some cases the symptoms may have been due to concurrent genital infection, but 52.5 per cent. of those in whom only gonorrhoea was detected had symptoms, which were generally mild. There were two cases of salpingitis, two of bartholinitis, and one of gonococcal septicaemia.

TABLE I I Percentage of women with gonorrhoea who had symptoms

\begin{tabular}{|c|c|}
\hline Reason for attendance & Percentage with symptoms \\
\hline $\begin{array}{l}\text { Contact of man with gonorrhoea } \\
\text { Of own accord } \\
\text { All other }\end{array}$ & $\begin{array}{l}38 \cdot 4 \\
92 \cdot 5 \\
61 \cdot 5\end{array}$ \\
\hline $\begin{array}{l}\text { Diagnosis } \\
\text { Gonorrhoea and trichomoniasis } \\
\text { Gonorrhoea and candidosis } \\
\text { Gonorrhoea only }\end{array}$ & $\begin{array}{l}59 \cdot 5 \\
58 \\
52 \cdot 5\end{array}$ \\
\hline All & 53.5 \\
\hline
\end{tabular}

Fourteen patients who attended as contacts of men with non-specific urethritis (NSU) were found to have gonorrhoea.

\section{INCIDENCE OF INFECTION IN CONTACTS OF MEN WITH} GONORRHOEA

127 new patients attended because they were thought to be contacts of men with gonorrhoea and $98(77 \cdot 4$ per cent.) were found to be infected. Of the remaining 29 patients, more than half had three or more examinations (Table III) which were thought to be 
adequate to exclude the diagnosis of gonorrhoea. Although it is not possible to be certain that all the patients were correctly diagnosed, it seems likely that they were as none of them returned later as contacts of men with gonorrhoea or with complications of the disease. None was treated on epidemiological grounds.

TABLE II I No. of weekly tests on uninfected contacts of men with gonorrhoea

\begin{tabular}{|c|c|c|c|c|c|c|}
\hline No. of weekly tests & 1 & 2 & 3 & 4 & 5 & Total \\
\hline $\begin{array}{l}\text { Number of patients } \\
\text { Total number of tests }\end{array}$ & $\begin{array}{l}3 \\
3\end{array}$ & $\begin{array}{l}10 \\
20\end{array}$ & $\begin{array}{l}13 \\
39\end{array}$ & $\begin{array}{l}2 \\
8\end{array}$ & $\begin{array}{l}1 \\
5\end{array}$ & $\begin{array}{l}29 \\
75\end{array}$ \\
\hline
\end{tabular}

\section{TREATMENT FAILURE AND RE-INFECTION}

534 tests were made on 191 patients who returned for follow-up (Table IV). Fifteen defaulted, five of them before treatment, and could not be traced. Three patients were followed up elsewhere. Nine cases of gonorrhoea were detected, a recurrence rate of 4.7 per cent. (Table V). A careful examination of the case histories indicated whether the recurrence was likely to be due to treatment failure or to re-infection. Of the four cases which seemed to be due to treatment failure-one of which had received Kanamycinthree were detected at the first follow-up test, but the other not until the fourth follow-up test. Five patients were considered to have become re-infected. This was detected at the first follow-up test in one patient who had intercourse with her untreated boy-friend during the first week after treatment. The other four patients had at least one negative follow-up test before infection was detected and their histories suggest that re-infection was likely. Two of them were extremely promiscuous, another had had intercourse with her boy-friend, who had defaulted from follow-up, and the other had had intercourse with her boy-friend, whom she had probably re-infected during the 6 weeks delay before she visited a clinic after receipt of a contact slip.

TABLE IV No. of weekly follow-up tests on 204 women treated for gonorrhoea

\begin{tabular}{|c|c|c|c|c|c|c|c|c|}
\hline $\begin{array}{l}\text { No. of follow-up } \\
\text { tests }\end{array}$ & 0 & 1 & 2 & 3 & 4 & 5 & 6 & Total \\
\hline \multirow{2}{*}{$\begin{array}{l}\text { No. of patients } \\
\text { Total number of } \\
\text { tests }\end{array}$} & 13 & 14 & 46 & 101 & 26 & 3 & 1 & 204 \\
\hline & 0 & 14 & 92 & 303 & 104 & 15 & 6 & 534 \\
\hline
\end{tabular}

TABLE V No. of follow-up tests before nine cases of recurrence of gonorrhoea were diagnosed

\begin{tabular}{llllll}
\hline Number of follow-up tests & & 1 & 2 & 3 & 4 \\
\cline { 1 - 4 } \cline { 3 - 6 } Number of recurrences & & 3 & 1 & 1 \\
due to probable re-infection & & 1 & 3 & 1 & 0 \\
due to treatment failure & & 3 & 0 & 0 & 1 \\
\hline
\end{tabular}

\section{CONCURRENT GENITAL INFECTIONS}

Table VI shows the other sexually transmissible infections which were detected in the 209 women with gonorrhoea. Candidosis was diagnosed in 81 (39 per cent), trichomoniasis in 47 ( 22.5 per cent.), and early latent syphilis in one case. More than half the cases of candidosis were not detected until after penicillin treatment had been given. Patients with gonorrhoea had a higher incidence of trichomoniasis than the female patients as a whole, 11.4 per cent. of whom were infested with the parasite.

TABLE VI Other genital infections diagnosed in 209 women with gonorrhoea

\begin{tabular}{lrll}
\hline Other genital infections & & No. & Per cent. \\
\cline { 1 - 1 } Candidosis & 81 & & 39 \\
Trichomoniasis & 47 & & 22.5 \\
Genital warts & 5 & \\
Genital herpes & 3 & \\
Pediculosis, scabies & 2 & \\
Syphilis (early latent) & 1 & \\
\hline No other infection & & 95 & 45.5 \\
\hline
\end{tabular}

\section{Discussion}

The majority of women attending the clinic were tested for gonococcal infection at least three times at weekly intervals. Of those patients found to be infected, the disease was detected in 98 per cent. by two examinations. In cases in which the infection was detected only by culture ( 39 per cent.) there was usually about one week's delay before treatment. However, in the majority of cases, diagnosis and treatment were completed within 8 days of the first attendance. These results compare favourably with earlier results reported by Catterall (1970), when only 86 per cent. of infected women were diagnosed after two examinations. The increased rate of detection was probably due to improved culture media and diagnostic methods, and it is of interest that these results were obtained without the addition of antibiotics to the culture medium. As a result of these findings it has been possible to decrease the number of examinations of women not thought to be contacts of men with gonorrhoea from four to two. Three examinations are recommended for the relatively small number of women who attend as contacts. This procedure also serves to monitor the efficiency of the cultures.

More than half of the infected women $(53.5$ per cent.) were symptomatic. Although the symptoms were often mild they were not thought to be imaginary. For comparison, the incidence of symptoms was calculated in a group of women who had been requested to attend the clinic because they were contacts of men with NSU. Only 22 per cent. of them were symptomatic. The high incidence of symptoms in women with gonorrhoea could not be accounted 
for by the high incidence of other genital infections. Chapel and Smeltzer (1975) found that 64.6 per cent. of women with gonorrhoea had urogenital symptoms, whereas Schroeter and Lucas (1962) reported that only 20 per cent. of women with gonorrhoea were symptomatic.

22 per cent. of women who were thought to be contacts of men with gonorrhoea were found to be uninfected. This is a much higher percentage than that reported by Hare (1974), who found that only 2.5 per cent. of female source contacts were not infected. However, the contact group at James Pringle House included all suspected source contacts as well as all probable secondary contacts, and thus may have included some who were not exposed to infection. The high incidence of gonorrhoea in contacts emphasizes the importance of contact tracing in control of the disease.

Although the majority of infected women attended because they were thought to be contacts, there were many who came of their own accord when they developed symptoms. Most of them had been to the clinic before, often with other types of genital infection, and it is possible that the previously favourable treatment and management encouraged them to visit the clinic when they developed the mild symptoms which may occur in gonorrhoea.

Epidemiological treatment of contacts of men with gonorrhoea is a routine practice in some clinics (Willcox, 1972). The difficulty in diagnosing the disease in women and the high default rate of certain patients with gonorrhoea have been given as reasons for treating women contacts at their first attendance. At this clinic the default rate is low and contacts of men with gonorrhoea are not treated without supporting evidence from smears and cultures. In this group of patients, only five ( 2.4 per cent.) defaulted before treatment, but if treatment had been given to contacts before the culture results were known then two of them would have been treated. On the other hand, 29 other contacts who were found to be negative by repeat examinations would have been treated unnecessarily.

The default rate after treatment was also small. Only ten (4.9 per cent.) of 204 women who had been treated were not followed up either in this clinic or elsewhere. A large number of follow-up tests were performed and nine cases of gonorrhoea were detected. Four of these were thought to be due to treatment failure and all but one were detected at the first examination. There is evidence that the other five cases were the result of re-infection. Except in one case, in which the patient had resumed intercourse with her boy-friend within a week of treatment, the patients had at least one set of negative tests before the infection was detected. It may be that repeated examinations to detect treatment failure are relatively non-productive and not cost-effective, but it is also important to establish whether re-infection could have occurred, because of asynchronous treatment of known partners or an asymptomatic undisclosed contact. In such cases repeated examinations should be performed in order to exclude these possibilities and renewed efforts should be made to diagnose and treat their contacts.

The experience described in this paper indicates the necessity for constant vigilance and quality control of the methods employed in the diagnosis of gonorrhoea in women.

E.J.C. was in receipt of a grant from the Department of Health \& Social Security.

\section{References}

Catterali, R. D. (1970) Brit. F. vener. Dis., 46, 122

Chapel, T. A., and SMel TZER, M. (1975) Ibid., 51, 25

HARE, M. J. (1974) Ibid., 50, 437

SCHROETER, A. L., and LUCAS, J. B. (1972) Obstet. and Gynec., 39, 274

WillCox, R. R. (1972) W.H.O. Document WHO/VDT/ 72.381 